\title{
ESTRUCTURAS SOCIALES Y ALTERNATIVAS POLÍTICAS EN AMÉRICA LATINA
}

\author{
Juan Maestre Alfonso*
}

\begin{abstract}
RESUMEN
La importancia y centralidad de las estructuras sociales se evidencian aún más en aquellas sociedades en las que los problemas sociales junto a factores culturales o históricos originan distancias y diferencias socioculturales agudas. Tal es el caso de América Latina donde se manifiestan, principalmente, dos tipos de estructura social: la evolucionada y la arcaica o tradicional. La pertenencia a una $\mathrm{u}$ otra posibilita o debilita las diversas opciones políticas y económicas. Su olvido o ignorancia por parte de los poderes públicos, así como la resolución del problema social aparecen como un defecto que resulta ineludible.
\end{abstract}

\section{PALABRAS CLAVE}

Estructura social, américa latina, sistemas políticos, cambio social, relaciones internacionales, globalización.

\begin{abstract}
The Importance and centrality of social structures becomes more evident in those societies in which social problems, along with cultural or historical factors, are the cause of deep sociocultural differences or social distance. This is the case in Latin America, where two kinds of social structures can be found: modern and archaic or traditional. Belonging to one of them or to the other will reinforce or weaken the choices for economic and political options. An apparently inevitable failure of most public administrations is their tendency to forget or ignore those situations, or even to address and solve the social problem.
\end{abstract}

\section{KEY WORDS}

Social structure, Latin America, political systems, social change, international relations, globalization.

"Las clases sociales son para las sociedades europeas o algo por el estilo, no para los Estados Unidos de América. Nosotros no vamos a estar divididos en clases". La frase procede, ni más ni menos, que de Bush; el padre; al que algunos calificamos de el bueno. En cualquier caso, con una family tan proclive a la ocupación de altas magistraturas se me ocurre que la clase social sí tiene algo que ver en la superpotencia mundial.

\footnotetext{
* Catedrático de Sociología de la Universidad de Sevilla
} 
De todas formas, ironías aparte, que manifieste una opinión de ese género quien goza de la capacidad de canonizar sus expresiones y elevarlas al repertorio del pensamiento único, o sino único si preponderante, no deja de ser importante. Resulta significativa y sintomática de orientaciones y trayectorias con capacidad de poder ser adoptadas como proyectos de modelos políticos. Podemos concluir que tal tipo de parecer no sólo ignora contextos sociológicos, sino que expresamente los minimiza. Quizá los anule.

Predomina un culto a la nueva Santísima Trinidad: mercado, empresa y capital. El mercado como Dios Padre. La empresa convertida en sufrido Dios Hijo, y el capital, hoy volátil, versátil, invisible y merced a los malabarismos financieros en el marco de la globalización, como el moderno símbolo colombófilo del Espíritu Santo. Conjuntan un nuevo marco de referencia y marginan a otros vectores de la historia. Weber versus Marx o la Escuela de Frankfurt frente al funcionalismo sistémico; teoría de la dependencia o teoría de la modernización. Nadie ha negado como hasta ahora el protagonismo social.

Alexis Tocqueville quedó maravillado de los recursos sociales de que disponía la Democracia en América -la del Norte- arquetipo, entonces, del modelo moderno de producir y reproducir equilibrios políticos. Pero de eso hace ya tiempo.

Cuando el Tercer Mundo se convierte en protagonista político, económico y social a nivel internacional y el horizonte del "desarrollo" se dibuja como la expectativa universal, se solicita un dictamen sobre los problemas de ese mundo, que no es ningún tercero, sino una parte del nuestro y además integrado por la inmensa mayoría de sus componentes. Es Galbraight quien preside la comisión que adoptó su nombre y a la cual se le solicitó el dictamen. Concluyó que para Asia el mayor problema era su agobiante población. África localizó su punto débil en la carencia de cuadros. Recordemos la llegada de la independencia del Congo con una docena de licenciados. Mientras que en América Latina, precisamente el territorio respecto al que dirijo ahora mi preocupación, son el tipo de las estructuras sociales, el más significativo obstáculo para acceder a ese proceso de procesos que designamos como "desarrollo".

No obstante, ni en el orden analítico, ni en el de las expectativas observamos que actualmente aparezcan inquietudes semejantes. A los factores sociales, insertos o no en las estructuras no se les presta atención. Permanecen diluidos en el culto a una libertad circunscrita por el triángulo divino de la nueva Santísima Trinidad. Un individualismo y la degradación solidaria convertidos en parámetros de un orden social que gravita entre el desorden social y el orden asocial.

La búsqueda de utilidad individual se acepta ya no como un hecho cultural, sino como una parte ideal integrante de la moral; de lo correctamente aceptable; de lo deseable para la buena marcha de la res-pública, que hubieran dicho nuestros clásicos e ilustrados. 
Como señala Ricardo Petrella la sociedad está entendida como un conjunto de transacciones individuales. Es una red; más bien ha sido sustituida por una red de relaciones económicas. El núcleo societario basado en la solidaridad ha sido modificado por un ámbito para la competición. ¡Qué gane el mejor! De la selección de los mejores, se piensa, saca provecho el conjunto social, incluso los peores y hasta los que no compiten, los polizones de ese sistema. Todos se benefician de la mejoría general. Si el mercado, como lo definen los economistas, es el espacio ideal para el encuentro de oferentes y demandantes, la sociedad, sobre todo la global, a la que podemos acceder merced al nuevo orden económico y a la revolución de las comunicaciones, se trasmuta actualmente en el lugar ideal para la optimización de los intercambios. Vivimos en un gigantesco mercado donde las posibilidades de elección son tan amplias como el repertorio mundial. Así se piensa y así se dice...

Los muchos que participan de estas concepciones discurren de modo que captan, como si fuera una trampa, una de las categorías más fundamentales del pensamiento Occidental: la libertad. Y la manipulan a su antojo. De la posibilidad de elegir se llega a la capacidad de ser libre. Sólo se es libre si se puede elegir, argumentan en este tipo de discurso. Cuando más se puede elegir más libre se es. Bush, el hijo -de momento- ha llegado a afirmar: "abrimos mercado, abrimos libertad". Y en Monterrey la libertad de mercado se equiparó en un mismo orden de exigencia a la práctica de la democracia.

Es también Pertrella quien nos dice, críticamente, que la institución que permite esa libertad es la empresa. Así se asciende a fundamental -de fundamento; donde se apoya el resto de la construcción- la libertad de empresa. Luego el capital, principalmente el financiero será quien asigne el tipo de valoración y de utilidad socio-global. Así se nos conduce a un sistema de valores retroalimentado por el capital.

Es lógico que de acuerdo con este pensamiento se origine la omisión de lo social. Y fruto de esta teoría aparece la práctica de establecer relaciones internacionales en las que prima, o priva, lo económico. Es un proceso que podemos verificar en las integraciones regionales, principalmente en las más recientes y en concreto en las americanas. Si en la Unión Europea esta "filosofía" aparece mas mitigada, que no ausente ${ }^{1}$, se debe a que es mucho más antigua, anterior en su origen a este tipo de raciocinio postmoderno, y a la influencia que en ella tuvo el rosa pálido de los que aceptaron el estado de bienestar, y también, en su momento a tener que competir, al menos dialécticamente con el rojo sangre de su far west.

Este ha sido el caso de América, en concreto de América "Latina". Subrayo lo de Latina para no caer en la brutal generalización que nos tiene acostumbrado Bush -el hijo...- entre otros muchos, incluido algún prominente español de atribuir en exclusividad a América, lo americano y los americanos, a las tierras y gentes muy importantes cuantitativa y cualitativamente, pero no únicas, de Estados 
Unidos. Estimo que históricamente no se ha asumido, en lo que a política regional se refiere, una consideración de lo social ni siquiera parcial.

La omisión es tanto más llamativa en cuanto la entidad del problema social en América Latina es acuciante. Convulsiones sociales han sacudido a la práctica totalidad de los estados latinoamericanos y acontecimientos de este carácter han configurado políticamente a muchas naciones. México, Bolivia, Argentina, Cuba, Nicaragua... entre otros países son o han sido elocuentes ejemplos de este proceso. La rebelión de los esclavos que dio lugar a la creación de Haití, como primer país libre y soberano de América, después de Estados Unidos, fue sintomática de una situación que ha estado gravitando en el acontecer latinoamericano. Es muy difícil que la sombra del problema social no se proyecte en la mayoría de los sucesos políticos, desde los más remotos a los más recientes. Incluso puede señalarse que tal influencia está más patente según se avanza en el tiempo. Se trata de un fantasma aún no borrado de los escenarios latinoamericanos. Ni es fruto de leyenda, ni constituye un residuo socio-histórico, ni está representado por un segmento secundario de la realidad social. Un frecuente recurso demagógico. ¡Puede ser! Pero en todo caso se trata de la demagogia de los hechos.

Las expectativas de cambio no se configuran oficialmente, y generalmente como búsqueda de incrementos de justicia, participación o bienestar, como viene sucediendo en Europa, al menos en una parte importante de ella y sólo desde hace algún tiempo, sino, a lo máximo, como intentos de evitar o reducir la injusticia, la explotación o la exclusión. No es lo mismo. Se parte de puntos de salida bien diversos y las metas son las caras opuestas de una misma moneda.

La II Declaración de La Habana repertoriaba a principios de los sesenta una situación. Allende, por poner un ejemplo, señalaba diez años después que esos problemas continuaban vigentes y es más que incluso habían aumentado. Aún después, desde la CEPAL decía su presidente, con palabras que no fueron publicadas en La Habana, sino en el Chile de Pinochet: “...hay más de 300 millones de habitantes. De ellos alrededor de 100 millones viven en condiciones de extrema pobreza, y de éstos 65 están en zonas rurales marginados de los mercados. Amplios grupos están marginados por razones étnico-culturales y es preciso realizar grandes esfuerzos para integrarlos a la sociedad y, por otra parte, los que ingresaban en las ciudades, si bien han recibido algunos de los residuos de la sociedad moderna, están relegados en su mayoría a cordones de miseria que contrastan violentamente con la riqueza de los grandes centros urbanos..." Se trata de dichos y de hechos, sin que contrariamente a lo que reza el refrán castellano exista ningún trecho. Son datos y argumentos que habrán podido ser utilizados demagógicamente, quizá hipócritamente, posiblemente amparando u ocultando otros peores, pero que en modo alguno nadie, ni nunca han negado, aunque, como vengo señalando, si sea frecuente que se ignoren. Recientemente la CEPAL ha estimado que el 48 por cien de la población latinoamericana vive por debajo del umbral de la pobreza, allí el 10 por ciento recibe el 48 por cien de la riqueza mientras que el 10 por cien más pobre 
sólo el 1,6 por ciento. Desigualdades que originan que existan países en la región que dediquen el 15 por cien de su PIB a pagar los resultados de la violencia o que el importe de la seguridad "privada" -recordemos que América Latina posee una tasa de homicidio seis veces superior a la correspondiente a la media mundial- sea muy superior al gasto público en sanidad.

Así, si se opina que considerar las clases sociales no sea algo pertinente, o como dijo el "Gran Jefe" ni adecuado para América. Si el problema social por grave que resulte se relega al desván de los trastos inútiles las estructuras sociales que engloban, entre otras cosas el caldo de cultivo del problema social, no reciben mejor trato. Se piensa que constituye elementos propios de una erudición académica.

No obstante las estructuras sociales son piezas esenciales para el dictamen del estado de salud social, política y económica de cualquier país. Pero también son imprescindibles para proceder a la descripción de estos países desde un punto de vista estático y a partir de esa focalización analítica proponer las medidas políticas adecuadas. Se convierten en catalizadores del cambio. Según se manifiesten unos u otros perfiles en cada estructura social, será posible o no alcanzar determinadas metas u objetivos. Se convierten en factores de freno o aceleración al cambio. O visto desde otra perspectiva, el cambio de las estructuras puede convertirse en el instrumento eficiente para el metabolismo socio-político. Quizá sea la conditio sine qua-non para alcanzar las metas deseadas. Es por esto por lo que insisto ahora, como antes y haré después, en lo atrevido, por no decir peligroso, de ignorarlas y no emplearlas en las políticas de integración regional. Las estructuras tienen capacidad de generar problemas, pero también de solucionarlos.

¿Pero a qué nos referimos cuando mencionamos el término, un tanto técnico por cierto, de estructura social? Existen parcelas de su contenido que resultan transparentes para la mayoría de los mortales. También sobre algunos de sus conglomerados conceptuales existe consenso. Sin embargo, está muy lejos de que se produzca unanimidad en su definición, ni incluso entre el colectivo de los especialistas en Ciencias Sociales. Posiblemente, entre éstos menos que entre los profanos a estas disciplinas.

El concepto estructura es una emanación del de estratificación. Tanto de uno, como de otro existen innumerables puntos de vista. No obstante resulta abrumador el número de especialista de las Ciencias Sociales que aceptan el triple concepto weberiano de las tres dimensiones: económica, social y política, correspondiendo a los tres elementos básicos de la estratificación: la clase, el status y el poder. Por su parte otro magnate de la teoría sociológica, Talcott Parsons, definió la estratificación como la ordenación diferencial de los individuos que componen un sistema social dado y el orden de superioridad o inferioridad recíprocos que guardan sobre ciertos aspectos importantes.

Descendiendo al eje de nuestro interés, el de estructura, plasmación práctica de la estratificación, en los países de economía avanzada se solventa su definición resumiendo que se trata de la jerarquización entre los diversos componentes que 
integran la sociedad. Sin embargo, tal interpretación no aparece tan válida en las sociedades del Tercer Mundo en las que persisten factores históricos e inciden una serie de variables de índole cultural, política y económica más nutridos y compuestos por elementos tanto exógenos como endógenos. La nueva aportación de la globalización aquí, incluso, nos complica el panorama.

Fue un sociólogo brasileño, poco conocido, Costa Pinto, quien en los años 60 procedió a definir la estructura social, a mi juicio, con más corrección y con mayor grado de validez para la situación latinoamericana. Decía: "cuando hablamos de estructura social, nos referimos a una sociedad vista desde el ángulo de los hombres entre sí y de los hombres con las cosas materiales que lo rodean, relaciones interdependientes y generadas históricamente en la actividad social del grupo. De este modo toda estructura social se compone como mínimo de las tres partes siguientes, que son inseparables: por "base" una forma histórica de producción, por "cuerpo" un sistema de estratificación social -el modo y manera como se jerarquiza los grupos; interpreto por mi parte- y por "cúpula" un conjunto de instituciones y valores sociales cuya finalidad es sancionar y mantener integrado el sistema estrechamente interdependiente formado por estas partes".

Tal manera de concebir la estructura social tiene el acierto de incluir los presupuestos weberianos que en la asignación de importancia a lo económico coinciden con los marxistas, y además de incluir, lo que me parece más importante y original, factores históricos y los sistemas de valores.

La realidad socio-económica de América Latina se ha prefigurado por su origen colonial, continuado y perfeccionado por el neocolonialismo que ha configurado una relación de dependencia que el vigente sistema mundial de globalización ni niega, ni dota de elasticidad, pues, por mucho que resulte que todos somos dependientes queda igual de cristalizado un orden en el que cada actor nacional tiene un lugar y un papel que desempeñar. El imperio de la nueva Santísima Trinidad no quita barreras al cambio, sino que como la tradicional Santísima Trinidad informa que la práctica resulta inmutable y que luego "gane el mejor" el que unos corran a pie descalzo y otros en jet, es secundario.

Luego la cultura, con su sistema de valores y sus correspondientes códigos de comportamiento, integra otro componente esencial para, no sólo especificar el quien es quién y donde está en la pirámide social, sino también explica el cómo, tanto en perspectiva de presente, como de futuro.

Aún cuando son varios los factores de homologación entre los diferentes países de América Latina también es nutrido el repertorio de sus diferencias, aspecto que cuando no origina extremismos nacionalistas conduce a prescindir de este irrefutable metiendo en el mismo saco a realidades no sólo distintas, sino distantes. El creciente espíritu americanista, latinoamericanista, andino, bolivariano, etc., tan presente en las últimas décadas en fórmulas de regionalización o en expectativas de cambio radical -la palabra revolución está mal vista y peor oída y es peligrosa-, al menos en la actualidad. La mitomanía nacionalista frecuentemente 
anexa a un cierto racionalismo político es el escenario contrario. Lo paradójico es que no sea extraño que ambas coexistan.

De Gino Germani a Medina Echavarría pasando por Lambert, un europeo que transitó intensa y eficazmente por el análisis de la realidad latinoamericana, se han ofrecido diversas tipologías de las estructuras sociales latinoamericanas basadas en indicadores de modernización, de entidad del problema social, del carácter axial de algunos grupos sociales.

Inspirándome en algunas de ellas, considero que se pueden apreciar dos grandes bloques de estructura social en América Latina. Los países que pueden tipificarse por dominar en ellos una estructura social evolucionada y aquellos en los que cabe la designación de "tradicional". Por supuesto que existen situaciones de excepción, Cuba o Panamá; de transición; e incluso en las que caben ambas, sin que se trate situaciones insulares, más o menos presentes en todas las realidades nacionales: es el caso de Brasil.

Estimo que la inclusión de cada respectiva realidad nacional en un tipo viene dada por el resultado del perfil societal -incluidos los factores culturales. Son las diversas variables en su histórica combinación y entidad cualitativa las que aportan la resultante social y nos ofrecen el modelo preponderantemente vigente.

No asigno connotación necesariamente positiva al término "evolucionado", ni necesariamente negativa al "tradicional", aún cuando no puedo menos que reconocer el hecho de las ventajas objetivas y subjetivas del primero. Tampoco las sitúo en un continuo, aunque igualmente admito que el modelo evolucionado actualmente suele situarse en el horizonte deseado.

Determinados países se han moldeado participando de una serie de rasgos sociológicos y antropológicos que se asemejan a los del Atlántico Norte, o más bien del subsistema de la Europa Mediterránea. En ello radica su designación como evolucionada; por pura convención más que por convencimiento, pues me encuentro entre quienes ponen en tela de juicio la superioridad a largo plazo del arquetípico modelo urbano-industrial imperante. Son sociedades cuyo aspecto socio-cultural -en lo que respecta a lo económico es mas discutible-, se acerca al europeo.

En este tipo de sociedades determinados caracteres sociales, los valores, la solución de los conflictos, los resultados de una psicología compartida, la manera de enfocar el futuro, la entidad del problema social, el peso o no del legado histórico, los sistemas de relación y comunicación social, la orientación de modelos y proyectos, el peso de la sociedad civil en la dinámica de la historia contemporánea; el protagonismo más compensado entre diversos segmentos de la sociedad y en concreto por parte de la clase media y del proletariado; el estado de los consensos básicos, específico y político; y en particular la mayor permeabilidad -comparativamente, claro- entre esos consensos; la posesión de más elevados niveles de racionalidad en la tipificación weberiana, etc., han sido moldeados social, cultural y psicológicamente por la incidencia de acontecimientos sociales tales 
como una inmigración masiva, que a vehiculado otros factores de cambio; por las experiencias históricas, y puede ser que también por las características del nicho ecológico donde se han desarrollado.

Mientras en los otros países se produce una configuración social y cultural en la que no han influido los mismos factores, o lo han realizado de modo diferente; su entidad cuantitativa y cualitativa ha podido ser divergente o dotada de rasgos, no sólo diferentes, sino, en ocasiones, contrarios. Los códigos sociales y culturales poseen composición diversa. Sucede frecuentemente que en unos predominan los propios que, no sin cierto etnocentrismo, se califican como modernos o evolucionados y en los otros países los dominantes se perfilan con elementos coloniales, folk,... arcaicos en suma. El escaso grado de cohesión social y una diferente articulación ocasiona un alto grado de desvertebración no sólo social, sino étnica e incluso nacional. Puede darse la situación de que no exista una imagen colectiva de lo nacional que corresponda a los límites del estado y sí, por el contrario, a unidades territoriales más pequeñas o al solar de ciertos grupos étnicos.

Lo normal es que en este tipo de sociedades no se haya transitado por experiencias en la que los conflictos fueron solucionados por el imperio de una norma común o aceptada mayoritariamente o fruto del interés general, ni siquiera en aras del bien común, tantas veces manifestado a través de la ideología religiosa oficial. El "ranking" de las expectativas no suele ser el mismo que en el caso anterior y lo que es más importante puede ser que la forma de alcanzarlas aún lo sea más diversa. Las formas de participación, por encima de grupos locales o subculturales aparecen frecuentemente como excluyentes y no integrativas. Hay escasez de grupos sociales secundarios y las organizaciones formales son pocas y de objetivos muy simples o primarios. El lastre del pasado, de la historia, es a veces más que un condicionante un determinante. Frecuentemente se vive obsesivamente, irracional y mitomicamente anteponiéndolo a intereses generales y actuales. Los legados históricos están presentes incluso cuando se rechazan; quizá más que nunca en esas situaciones. A veces, en alguno de estos países aparece como real y vigente esa división que hace siglo y medio realizó Spencer de sociedades industriales y sociedades militares, pues parecen inmersas en ese segundo estadio.

Por mi parte estimo que el primer grupo de estructuras sociales posibilita el "desarrollo" entendido como el proceso que hace mejorar a las sociedades en si misma, solucionando sus problemas globalmente y no exclusivamente incrementando algunas variables económicas o logrando sectorialmente aspectos de modernización que afectan a grupos sociales minoritarios. Las mejoras tienen que sentirse, sino en todo sí, en la mayoría y en los más importantes segmentos de la sociedad; en sus categorías de sexo, edad, raza, estado físico, adscripción ideológica... y por supuesto, capacidad económica y acceso a las fuentes de poder. No basta la implantación de fórmulas o de estructuras democráticas, ni tan siquiera la adopción de unos elevados niveles de consumo. Aún cuando uno y otro no sólo sean importantes, sino también necesarios; pero no lo son suficientes. La dimensión 
económica no es la única en el desarrollo, ni tampoco tiene ese carácter la política. La social no debe ignorarse. Estas orientaciones deberían integrar una nueva Santísima Trinidad. Igualmente, no debe focalizarse con perspectiva de presente, sino también, quizá aún más, de futuro; lo que exige respeto al medio físico y cultural que debemos legar a generaciones futuras.

La estructura social "tradicional" no impide, pero si dificulta el acceso a niveles de desarrollo tal como los concebidos anteriormente. No faltan opiniones contrarias. Yo mismo me las he encontrado en mi vida profesional y política. Hay quien piensa que cuando más agudas sean las contradicciones más capacidad hay para lograr cambios radicales. Nuestra historia inmediata demuestra la falacia de tal afirmación que ha resultado trágica para muchos miles de personas.

La modalidad estructural evolucionada posibilita, que ya es bastante, aunque ni condiciona, ni determina y menos aún impide retrocesos. Chile, Argentina o Uruguay constituyen elocuentes ejemplos de estructura social evolucionada y que fueron capaces de caer en el foso de una importante degeneración política y económica. No obstante, contienen capacidades para evolucionar en mayor grado que otras sociedades.

Reinsertándonos en el espacio de los procesos de integración regional se puede observar, como ya indique anteriormente, la omisión de la dimensión social. No ya de las clases sociales como afirmaba el señor Bush, sino de prácticamente todos sus aspectos incluido el volumen y origen de la problemática social. ¿Qué decir de la falta de toma en consideración del complejo de las estructuras sociales?

Tal tipo de omisión o de acción, pues puede ser producto de un cálculo político, tiene varios defectos. Ocasiona la carencia del cemento requerido para que el edificio de la integración fragüe y subsista. Relega la que debería ser una importante meta. Mezcla unidades que pueden resultar no homogéneas, aunque admito sí pueden ser complementarias. Y desprecian un eficaz instrumento para lograr las expectativas de cambio.

Es difícil que con tal complejo de acciones y omisiones resulten más que amalgamas forzadas los actuales proyectos de integración regional en América Latina. El inconmensurable gracejo popular de los brasileños califica a sus instituciones y leyes con un pra inglés ver. Para dar una imagen. Pueden que exageren; pero no del todo. $\mathrm{Y}$ es cierto que estos proyectos corren el peligro unos más y otros menos -de oscilar entre el deseo y la imagen. Pensemos que a los defectos que señalo aquí, hay que agregar todos aquellos que si son objetos de preocupación por los técnicos gubernamentales y los funcionarios regionales y que son los procedentes del desajuste institucional y legal entre los diversos estados y el hecho de que alguna de estas deseadas regiones multiestatales estén integradas por economías que no son complementarias; con poco que intercambiar entre ellas.

En cualquier caso, no se puede ser excesivamente crítico con las integraciones regionales latinoamericanas -de las cuales excluyo al Tratado de Libre Comercio, original y peculiar en ese universo. Se puede asegurar que es mejor esto 
que nada. Pero dichas las cosas de esta manera parece que nos agarramos al clavo ardiente de un pesimismo conformista. Pero de hecho se trata de un necesario punto de partida polivalente y que se orienta con sinceridad hacia objetivos que, además de necesarios, son prometedores. Las integraciones regionales constituyen embriones de grandes espacios económicos que facilitan los beneficios de las economías de escala. Y son macroámbitos convivenciales que promueven intercambios de ideas, generan una clase funcionarial de carácter internacional con objetivos comunes y creciente eficacia. Y, quizá lo principal, que trastocan esa tendencia histórica en América Latina de ignorancia, cuando no en enemistad de baja intensidad, entre países vecinos protagonizada particularmente por sus elites políticas y culturales.

Sin embargo, es igualmente imprescindible que las regiones establezcan metas sociales y que instrumentalicen recursos de carácter sociológico. El cambio estructural y su consiguiente homologación debe de ser más que un deseo -hoy desafortunadamente no llega ni a ese nivel- y sí un objetivo y con políticas concretas establecidas para su alcance.

De no ser así me temo que se caiga en lo que denomino el síndrome de Morazán. Como se sabe este insigne personaje fue un prócer no en Centroamérica sino de Centroamérica. Acabó siendo fusilado por la causa centroamericana, precisamente en tierras y por gentes muy próximas a él. Pero poco tiempo después se decidió hacerle un monumento en el punto más simbólico y central de la capital de su país. Se pensó realizar una estatua, pero no se conocían, escultores capaces de confeccionar allí esa obra. Para paliar el problema una comisión se marchó a Paris para encargar el monumento, pero se gastó buena parte del dinero y se redujo sensiblemente el presupuesto. No se podía hacer frente al gasto de encargar una estatua. Pero si había unas cuantas estatuas de generales napoleónicos que ya no decían nada a la historia de Francia y que estaban relegadas a los almacenes. Se compró una de ella y se instaló frente a la catedral. Hoy en las fechas más simbólicas se realizan grandes demostraciones cívicas ante la estatua ecuestre de quien en realidad fue un olvidado general del otro lado del océano. De todas formas siempre resultará mejor a que en la catedral instalen a la nueva Santísima Trinidad.

\section{NOTAS}

${ }^{1}$ Comunidad del Carbón y del Acero, Mercado Común Europeo, la Europa de los Capitales G8... y la constatación empírica del monstruoso -en el sentido técnico de la palabracrecimiento y perfeccionamiento de lo económico y lo insuficiente de lo social. 